\title{
Retraction Note to: Therapeutic management of trypanosomosis with ophthalmic involvement in a dog
}

\author{
S. K. Behera ${ }^{1} \cdot$ K. Sarma ${ }^{1} \cdot$ Parthasarathi Behera $^{2} \cdot$ M. Ayub Ali ${ }^{2}$
}

Published online: 6 April 2018

(C) Indian Society for Parasitology 2018

\section{Retraction Note to: J Parasit Dis (Oct-Dec 2017) 41(4):1162-1165 https://doi.org/10.1007/s12639- 017-0953-z}

The authors have retracted this article [1] because it has been previously published [2]. This article is therefore redundant. All the authors agree to this retraction.

\section{References}

1. Behera SK, Sarma K, Behera P, Ali MA (2017) Therapeutic management of trypanosomosis with ophthalmic involvement in a dog. J Parasit Dis 41(4):1162-1165

2. Behera SK, Ali MA, Behera P (2017) Therapeutic management of trypanosomosis with ophthalmic involvement in a dog. Intas Polivet 18(1):180-182

The original article can be found online at https://doi.org/10.1007/ s12639-017-0953-z.

S. K. Behera

drsuvendu.kumar@gmail.com

1 Department of Veterinary Medicine, College of Veterinary

Sciences and Animal Husbandry, Central Agricultural

University, Selesih, Aizawl, Mizoram 796 014, India

2 Department of Veterinary Physiology and Biochemistry,

Central Agricultural University, Selesih, Aizawl, Mizoram

796 014, India 